\title{
COMO OS PODCASTS PODEM AUXILIAR A COMPETÊNCIA AUDITIVA NO ÂMBITO ENSINO-APRENDIZAGEM DE ESPANHOL COMO SEGUNDA LÍNGUA?
}

\author{
Juliana da Silva Fernandes \\ Aluna da Licenciatura em Espanhol do IFRN \\ julianasilvafernandes@gmail.com \\ Maraísa Damiana Soares Alves \\ Aluna da Licenciatura em Espanhol do IFRN \\ maraisasa@yahoo.com.br
}

\begin{abstract}
RESUMO
Este artigo apresenta a tecnologia do podcast como ferramenta educativa e tem por objetivo demonstrar algumas possibilidades de sua utilização. Introduz a idéia do desenvolvimento da compreensão auditiva através das potencialidades desse recurso para o ensino de línguas estrangeiras. De fácil utilização, os programas estão disponíveis na internet e podem ser copiados para o próprio computador ou para tocadores de mp3, facilitando o conhecimento das diferentes variantes do idioma. A pesquisa bibliográfica elaborada se concentrou nas questões específicas do ensino-aprendizagem de espanhol, no debate entre tecnologia e educação e no uso didático do podcast. Por fim, a conclusão obtida é que, numa perspectiva não-crítica, a tecnologia pode auxiliar o desenvolvimento das competências comunicativas do estudante de espanhol como segunda língua.
\end{abstract}

Palavras-chave: podcast, competência auditiva, TIC, espanhol.

\section{RESUMEN:}

Este artículo presenta la tecnología del podcast como herramienta educativa y tiene por objetivo demostrar algunas posibilidades de su utilización. Introduce la idea del desarrollo de la comprensión auditiva a través de las potencialidades de este recurso para la enseñanza de lenguas extranjeras. De fácil utilización, los programas están disponibles en Internet y pueden ser copiados para los computadores o para los reproductores de mp3, facilitando el conocimiento de las diferentes variantes del idioma. La investigación bibliográfica elaborada se concentró en las cuestiones específicas de la enseñanzaaprendizaje del español, en el debate entre tecnología y educación y en el uso didáctico del podcast. Por fin, la conclusión obtenida es que, en una perspectiva no crítica, la tecnología puede auxiliar el desarrollo de las competencias comunicativas del estudiante de español como segunda lengua.

Palabras clave: podcast, competencia auditiva, TIC, español. 


\section{COMO OS PODCASTS PODEM AUXILIAR A COMPETÊNCIA AUDITIVA NO ÂMBITO ENSINO-APRENDIZAGEM DE ESPANHOL COMO SEGUNDA LÍNGUA?}

\section{INTRODUÇÃO}

Esse artigo pretende discutir como a tecnologia dos podcasts pode auxiliar o ensinoaprendizagem do espanhol como segunda língua através do desenvolvimento de uma das quatro capacidades lingüísticas, a compreensão auditiva.

No entanto, a tecnologia é um recurso gradualmente integrado à educação. Em uma perspectiva histórica, a evolução aconteceu do quadro negro ao quadro branco, do retroprojetor ao projetor multimídia, do jornalzinho da turma ao blog na internet e essas inovações, se bem utilizadas, podem complementar o que é feito em sala de aula, mas não serão a salvação de uma educação com falhas. Somente com boa formação pedagógica e com domínio das competências comunicativas necessárias à profissão é que se pode pensar no mundo virtual como uma nova dimensão de ensino.

Por isso, nosso objetivo com esse trabalho é esclarecer, através de pesquisa bibliográfica, o potencial do podcast, essa nova tecnologia auditiva no campo educacional.

\section{O QUE É PODCAST?}

A palavra inglesa Podcast surgiu em 2004 e, literalmente, significa retransmissão de dados comprimidos, mas foi adotada no Brasil sem tradução. Podcast é uma nova tecnologia de distribuição de áudio que permite a qualquer pessoa produzir e disponibilizar programas exclusivamente pela internet.

Ou seja, é uma derivação do rádio com acesso virtual 24h de qualquer lugar do mundo e com a possibilidade de ser transmitido por streaming ${ }^{1}$. O formato utilizado é o mp3, que gera arquivos com tamanho reduzido e uma boa qualidade de som.

A grande ousadia dessa nova tecnologia é a junção do conceito que tínhamos de rádio com as tendências para as rádios no futuro, sobretudo com relação à comunicação horizontal (emissor $<->$ receptor).

Outro ponto importante é a crescente popularização dos podcasts a partir do barateamento de aparelhos tocadores (mp3 players e celulares de última geração), que possibilitam a mobilidade de qualquer mídia auditiva para fora do computador.

\section{COMO AS TECNOLOGIAS PODEM AUXILIAR A EDUCAÇÃO?}

\footnotetext{
${ }^{1}$ Pode ser traduzido como 'fluxo contínuo' e é uma forma de transmitir áudio e/ou vídeo em tempo real sem a necessidade de baixar o arquivo para iniciar a reprodução.
} 
Se o avanço nas pesquisas tecnológicas possibilitou o surgimento da Internet na segunda metade do século XX e o aperfeiçoamento desse sistema instituiu uma rede virtual de comunicação mundial, então pensar essa nova dimensão, significa dar à educação uma nova possibilidade para expandir seus limites. "As tecnologias de informação e comunicação (TIC) oferecem potencialidades imprescindíveis à educação e formação, permitindo um enriquecimento contínuo de saberes.” (SILVA, A. et al, 2003).

O mundo virtual representa uma revolução na possibilidade dos materiais didáticos e das técnicas de ensino-aprendizagem. Como afirma Erivaldo Silva et al (2003), na internet o estudante tem liberdade de pesquisar aleatoriamente o que mais necessita, promovendo diferentes formas de aprendizagem, por descoberta, por aproximação, entre outras.

Ou seja, a Internet é mais um recurso para o fomento da educação, importante não apenas pelo conhecimento gerado, mas também pelo caráter personalizado que a informação adquire.

A hipertextualidade altera a relação hierárquica entre docente e aprendiz, já que faz possível que o estudante possa aprender, investigar, estabelecer relações entre a informação, etc. abandonando assim o papel passivo de receptor da informação proporcionada pelo professor. (LANDOW, 1995 apud ANTÓN, 2007, web. tradução nossa)

No entanto, não se pode pensar que as tecnologias funcionam como 'agentes salvadores' de uma educação com falhas. A hipertextualidade ${ }^{2}$ auxilia, mas não educa. A responsabilidade da transmissão do conhecimento ainda está na escola e nos professores, que ajudados pelas inovações podem potencializar o alcance do que é passado em sala de aula, estimulando o aprendizado como um todo.

Precisamos refletir que por mais que os avanços aconteçam, eles não chegam de modo igualitário para todos. As possibilidades das TIC são subaproveitadas tanto por falta de investimento nas escolas públicas (em tecnologia e capacitação de pessoal para desenvolver as funções requeridas) quanto pela dificuldade de acesso de grande parte da população devido ao baixo poder aquisitivo. Mas não é o objetivo deste artigo a discussão acerca da inclusão digital.

\section{E QUAIS SÃO AS COMPETÊNCIAS REQUERIDAS NO ESTUDO DA LÍNGUA?}

Segundo o Marco comum europeu de referência para as línguas (2002), existem seis atividades comunicativas, entre elas, compreensão (auditiva e escrita), expressão (escrita e oral), interação e mediação. Todas essas atividades pertencem ao grupo da competência lingüística que inclui conhecimentos e destrezas lexicais, fonológicas e sintáticas. No entanto, para ser considerado fluente o aprendiz ainda precisa desenvolver duas habilidades, a competência sociolingüística, que se refere às condições socioculturais do uso da língua, e a competência pragmática que tem a ver com o uso funcional dos recursos lingüísticos, produção de funções da língua e atos da fala.

\footnotetext{
${ }^{2}$ Qualidade do hipertexto, ou seja, texto suporte que acopla outros textos através de links que conectam a construção de sentido, estendendo ou complementando o texto principal.
} 
Para Manuela Berges (2005, p.905, tradução nossa), “O processo de compreensão auditiva é fundamentalmente um processo mental invisível e, como tal, não o podemos observar e analisar com a mesma facilidade com que tratamos, por exemplo, a expressão lingüística”. Ela inclusive destaca o ato de escutar como um processo interativo de percepção e interpretação. Por isso, a grande motivação para que os professores de língua espanhola considerem os podcasts como ferramenta de ensino-aprendizagem está na dificuldade dos estudantes para reconhecer sotaques (variantes do idioma), perceber as divisões entre as palavras (término/início) e distinguir o estilo (mais ou menos formal).

Desenvolver a compreensão auditiva é, sobretudo, se tornar um 'ouvinte competente', termo que adotamos segundo a descrição de Rost (1990 apud BERGES, 2004, p. 908.), na qual o ouvinte aprimora sua competência ao aumentar:

- a quantidade de linguagem que pode compreender de uma só vez;

- a gama de acontecimentos que pode interpretar razoavelmente;

- sua consciência das dificuldades de compreensão;

- sua tentativa e habilidade de converter os casos de compreensão errônea ou deficiente em compreensão aceitável.

Conhecer esses dados técnicos auxilia o entendimento sobre a dinâmica por trás da compreensão auditiva, facilitando a atividade docente e dando embasamento para a elaboração de novos materiais. Aqui citamos apenas uma amostra do que já se possui acerca dessa atividade comunicativa.

\section{MAS COMO AGREGAR O USO DE PODCASTS AO ENSINO DE UMA LÍNGUA ESTRANGEIRA?}

Quando um aprendiz de língua estrangeira entra em contato com exemplos de podcasts gravados no idioma que ele estuda, surge um leque de possibilidades de aprendizado através do desenvolvimento de sua capacidade auditiva.

Para os estudantes de língua espanhola não é diferente. Ao realizar pesquisas em diretórios de podcasts ele está exposto às variedades dialetais do espanhol falado nos dois lados do oceano atlântico. E com isso pode perceber que nenhuma variação é menos legítima que a outra. Nesse tocante, a expansão cultural ganha muito com o caráter personalizado não só dos podcasts como da internet em geral.

As alternativas de aprofundamento em conhecimentos socioculturais de um estudante se multiplicaram. Hoje ele pode pesquisar sobre a retomada do cinema argentino ao mesmo tempo em que ouve música mexicana.

Além disso, importantes habilidades cognitivas e sociais podem ser obtidas durante o exercício de 'brincar de ter uma rádio', - caso o aluno deseje produzir seu próprio podcast - por exemplo, escrita de roteiros e o manejo das tecnologias para gravar e disponibilizar conteúdo na rede mundial de computadores.

Aqui citamos alguns diretórios de podcasts em espanhol para que se possa conhecer melhor como eles funcionam na prática. 
Podcastellano: http://www.podcastellano.com

Folcast.com: http://www.folcast.com

Podsonoro.com: http://www.podsonoro.com

Elpodio.com: http://www.elpodio.com

\section{CONSIDERAÇÕES FINAIS}

O aprendizado de outro idioma deve ser uma prática prazerosa. Saber realmente uma língua significa conhecer seus aspectos culturais com discernimento para respeitar as diferenças. O podcast vem para engrandecer esse intercâmbio cultural no mundo globalizado. Por isso, nossa intenção é desmistificar essa tecnologia que, se bem utilizada, pode ser companheira da educação. Esse recurso voltado para o ensino de línguas tem o intuito de formar ouvintes competentes habilitando estudantes mais fluentes. Pois, pensar uma das atividades comunicativas é também pensar no conjunto, já que desenvolvendo a competência auditiva as outras cinco habilidades lingüísticas também evoluem.

Por fim, é preciso reafirmar que tecnologia é só uma ferramenta, funciona como um meio para despertar interesse no aluno dentro e fora da sala de aula, porém não substitui a pedagogia e a didática.

\section{REFERÊNCIAS BIBLIOGRÁFICAS}

ANTÓN, Rosa. Laberintos digitales: una herramienta para la enseñanza y aprendizaje de ELE mediante e-learning. Madrid, 2007. Disponível em: http://www.mec.es/redele/Biblioteca2007/RosanaLarraz.shtml Acesso em 22 jul. 2007.

BERGES, Manuela. La comprensión auditiva. In: LOBATO, J.; GARGALLO, I. (org.) Vademécum: para la Formación de Profesores. Madrid: SGEL, 2004. p. 899-913.

GELADO, José. Mesa Podcasting. Sevilla, 2006. Disponível em: http://www.slideshare.net/jagelado/mesa-blogs-y-podcasts-unicienblog Acesso em 23 jul. 2007.

HIPERTEXTUALIDADE. In: Wikipedia. Disponível em: http://pt.wikipedia.org Acesso em: 24 jul. 2007.

KENSKI, Vani Moreira. O papel do professor na sociedade digital. In: CASTRO, Amélia Domingues; CARVALHO, Anna M. P. de. Ensinar a ensinar. São Paulo: Pioneira Thomson Learning, 2002.

\section{MINISTERIO DE EDUCACIÓN, CULTURA Y DEPORTE. Marco común europeo de} referencia para las lenguas. Madrid, 2002. Disponível em: http://cvc.cervantes.es/obref/marco Acesso em: 19 jul. 2007.

SILVA, Ângela et al. O Centro Federal de Educação Tecnológica do Rio Grande do Norte e as novas tecnologias de educação. In: TORRES, Patrícia (Org.). Pioneirismo em educação a distância: a experiência do Rio Grande do Norte. Natal: CEFET-RN, 2003. p.111-133. 
SILVA, Erivaldo et al. A educação a distância como modalidade de ensino do Procefet. . In: TORRES, Patrícia (Org.). Pioneirismo em educação a distância: a experiência do Rio Grande do Norte. Natal: CEFET-RN, 2003. p.159-190.

STREAMING. In: Television. $\quad$ Disponível http://televisioncombr.wordpress.com/tag/streaming Acesso em 22 jul. 2007. em: 